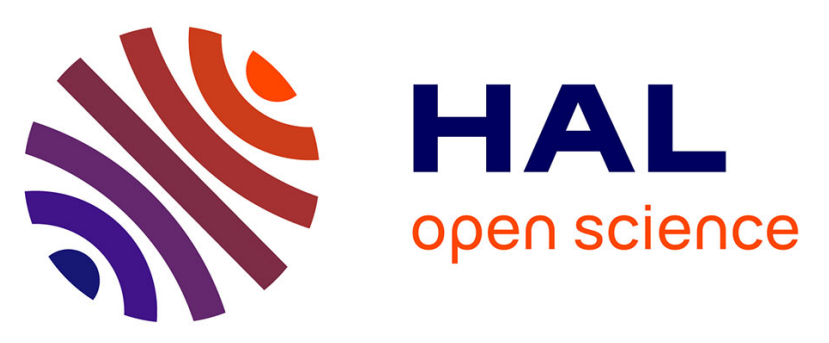

\title{
Beneficial Influence of Mindfulness Training Promoted by Text Messages on Self-Reported Aerobic Physical Activity in Older Adults: A Randomized Controlled Study
}

Nicolas Robin, Lucette Toussaint, Stéphane Sinnapah, Olivier Hue, Guillaume R. Coudevylle

\section{To cite this version:}

Nicolas Robin, Lucette Toussaint, Stéphane Sinnapah, Olivier Hue, Guillaume R. Coudevylle. Beneficial Influence of Mindfulness Training Promoted by Text Messages on Self-Reported Aerobic Physical Activity in Older Adults: A Randomized Controlled Study. Journal of Aging and Physical Activity, 2020, 28 (3), pp.406-414. 10.1123/japa.2019-0002 . hal-02378048

\section{HAL Id: hal-02378048 https://hal.science/hal-02378048}

Submitted on 10 Apr 2020

HAL is a multi-disciplinary open access archive for the deposit and dissemination of scientific research documents, whether they are published or not. The documents may come from teaching and research institutions in France or abroad, or from public or private research centers.
L'archive ouverte pluridisciplinaire HAL, est destinée au dépôt et à la diffusion de documents scientifiques de niveau recherche, publiés ou non, émanant des établissements d'enseignement et de recherche français ou étrangers, des laboratoires publics ou privés. 
Beneficial Influence of Mindfulness Training Promoted by Text Messages on Self-

2 Reported Aerobic Physical Activity in Older Adults: A Randomized Controlled Study

3

4 Nicolas Robin*, Lucette Toussaint**, Stéphane Sinnapah*, Olivier Hue*, and Guillaume, R.

5 Coudevylle*

6

7 *Université des Antilles; Faculté des Sciences du Sport; Pointe-à-Pitre; France.

8 ** Université de Poitiers; Université François Rabelais de Tours; Centre National de la

9 Recherche Scientifique; Centre de Recherches sur la Cognition et l'Apprentissage

10

11 Suggested running head: MINDFULNESS, PHYSICAL ACTIVITY AND OLDER ADULT

12

13 Correspondence concerning this article should be addressed to Nicolas Robin, Laboratoire

14 "Adaptation au Climat Tropical, Exercice \& Santé" (UPRES EA 3596), Campus Fouillole, BP 592, 97159, Pointe à Pitre Cedex, France. Mail: robin.nicolas@hotmail.fr;

16 Fax number: (00 33) 0590 48.31.70; phone number: (00 33) 059048.31 .69

17 
1 Inactivity is known to have harmful effects on the physical and mental health of older adults.

2 This study used a randomized parallel trial design to evaluate whether daily text prompts to

3 practice mindfulness would have a positive impact on the time that adults 50 years or older

4 spend in aerobic physical activity (APA).

5 Methods: Participants were recruited from a certified fitness centre and divided into

6 Mindfulness and Control groups. For 4 weeks, they were exposed to the experimental

7 conditions: with or without the morning text message. In the morning message condition, the

8 Mindfulness groups received a text message with the instruction to practice audio-guided

9 mindfulness for 10 minutes and the Control group received a placebo message.

10 Results: Participants practicing mindfulness reported significantly more weekly minutes of

11 APA and higher intrinsic motivation than the control participants.

12 Conclusion: Mindfulness training was effective at increasing APA duration and might

13 complement physical activity programmes.

14 Keywords: Mindfulness, electronic message, elderly, physical activity, motivation

15

16

17

Mindfulness Training Promoted by Text Messages Increases Self-Reported Aerobic Physical Activity in Older Adults: A Randomized Controlled Study 
According to the World Health Organization (WHO, 2011), physical inactivity is the

2 fourth leading risk factor for global mortality, accounting for more than $20 \%$ of cancer,

3 ischemic heart disease, lung disease and diabetes cases. It has been estimated to be

4 responsible of more than 3 million deaths per year (WHO, 2013). In contrast, physical activity

5 has many health benefits for individuals (Taylor, 2014) with a beneficial influence on ageing

6 on: Heart rate variability and executive performance (Albinet, Boucard, Bouquet, \&

7 Audiffren, 2010), premature mortality prevention (Charansonney, 2011). It also reduces

8 obesity, falls, cognitive impairements, osteoporosis and muscular weakness decrease (for a

9 review see McPhee et al., 2016). According to Warburton (2009), physical activity

10 corresponds to all time body movements leading to an increased energy expenditure from rest

11 that include transportation (walking, cycling), domestic (walking his dog, maintain the garden or vegetable garden), occupational (work-related), and leisure-time (exercises, discretionary or recreational time for sport, exercise, physical activity). However, it is important to note that many factors (e.g., social, cultural, economic, class, and/or race) can affect one's physical activity (Dionigi \& Gard, 2018). Therefore, it is important to note that this study is specific to the experiences of French middle class older people who have the means and ability to access a mobile phone and exercise regularly. For older adults, a minimum of 150 minutes of physical activity per week is recommended (WHO, 2013), including 75 minutes of vigorousintensity aerobic activity or an equivalent combination per week (Elsawy \& Higgins, 2010). However, according to Sun, Norman, and While (2013), less than $20 \%$ of adults between 50 and 64 years old and less than $16 \%$ of those who are older are meeting these recommendations. Finding effective, simple, easy to perform and innovative strategies (e.g., mental imagery or mindfulness) to encourage older adults to be more active is therefore an important public health concern (Denison, Vist, Underland, \& Berg, 2014; Hughes et al., 2011, Robin et al., 2017). 


\section{Mindfulness and Older Adults}

Mindfulness refers to a state of awareness and attention to the present moment (Bishop et al., 2004). It may include attention to mental, physical, and environmental stimuli, but with acceptance, non-judgement, and openness (Brown \& Ryan, 2003; Cox, Roberts, Cates, \& McMahon, 2018). According to Foutain-Zaragoza and Prakash (2017), mindfulness may be particularly useful for older adults because it seems to provide promising physiological, cognitive and emotional benefits. For example, Alexander, Langer, Newman, Chandler and Davies (1989) showed that a mindfulness group had higher cognitive flexibility, paired associate learning, and word fluency performances than a control group. Foutain-Zaragoza and collaborator (2017) suggested that mindfulness-based interventions might improve and/or prevent age-related declines in cognitive functions and brain structures. Moreover, these authors further suggested that mindfulness facilitates the enactment of useful emotionregulation strategies, enhances psychological well-being (Fiocco \& Mallya, 2015), and reduces perceived stress (Prakash, Hussain, \& Schirda, 2015), all of which might influence physical activity in older adults. Mindfulness can be performed at home and facilitated by the use of digital tools such as text message, and/or audio track (Norris, Creem, Hendler, \& Kober, 2018), on cell phone or digital tablet.

\section{Text Messaging, Motivation and Physical Activity in Older Adults}

Physical activity campaigns and health promotion strategies are of great interest because they can have a positive influence on behaviour (Leavy, Bull, Rosenberg, \& Bauman, 2011). Innovative strategies have been tested, such as active video games (Studenski et al., 2010), personalized videos (Vandelanotte et al., 2015), internet (Duncan et al., 2014), and mobile devices, leading to the concept of mobile health (Fong et al., 2016; Johnston, Hoffman, \& Thornton, 2014; O'Reilly \& Spruijt-Metz, 2013). According to Morton and collaborators (2015), text messaging can be a tool for health promotion based on the hypothesis that, like marketing strategies, these messages may prompt individuals to change 
1 their behaviours in a desired way (Cole-Lewis \& Kershaw, 2010; Fjeldsoe, Marshall, \&

2 Miller, 2009). Indeed, reviews on the effectiveness of text messaging in promoting physical

3 activity (Fanning, Mullen, \& McAuley, 2012; Joe \& Demeris, 2013) have found that text

4 messages can generate positive attitudes, feedback, and results (Antoine Parker \& Ellis, 2016;

5 Kim \& Glanz, 2013; Robin et al., 2017). As older adults have more access to cell phones than

6 other technologies and are increasingly using mobile phones and the internet (Anderson \&

7 Perrin, 2017; Joe \& Demeris, 2013), designing new ways to use these technologies to promote

8 health and physical activity has become an obvious research goal (Gell, Rosenberg, Demiris,

9 LaCroix, \& Patel, 2015; O'Reilly \& Spruijt-Metz, 2013). Recent studies have shown that

10 texting increases certain domains of self-reported physical activity (Antoine Parker \& Ellis,

11 2016; Kim \& Glanz, 2013; Muller, Khoo, \& Morris, 2016). For example, Robin et al. (2017)

12 showed that guided imagery texts delivered via cell phones were successful at increasing weekly minutes of aerobic physical activity (APA) among older adults, notably by enhancing

14 their motivation. However, the authors noted that differences in imagery ability (i.e., the capacity to generate mental images that differs among individuals) might be one reason why

16 people choose not to use imagery even when it could be beneficial. It therefore seems

17 important to find other and/or complementary strategies to enhance motivation and increase 18 physical activity in older adults.

\section{Intrinsic Motivation, Mindfulness and Physical Activity in Older Adults}

Self-Determination Theory (SDT, Deci \& Ryan, 1985) is one of the most commonly used theoretical frameworks in studies of individual's motivation, which includes a series of mini-theories of motivational properties, its antecedents and its consequences (Deci \& Ryan, 2008) and can be considered as a relevant framework in the context of motivation to practice physical activity (Boiché, Gourlan, Trouilloud, \& Sarrazin, 2016). SDT basically 
1 through their actions), external motivation (when the behavior is conceived as a mean to avoid

2 a negative result or to attain a positive one) and internal motivation (when peoples realize a

3 behavior for the satisfaction and pleasure they derive from it). According to SDT (Ryan \&

4 Deci, 2007), intrinsic motivation is the best predictor of adherence to physical activity

5 (Teixeira, Carraça, Markland, Silva, \& Ryan, 2012). Ullrich-French, González Hernandes and

6 Hidalgo Montesinos (2017) added that adherence is even higher when individuals are

7 motivated by the inherent rewards of the physical activity itself (i.e., enjoyment and

8

satisfaction when experiencing physical sensations and feelings of accomplishment when exerting effort) compared with external reasons (i.e., exercising to please other people or to lose weight). The authors evoked that to obtain rewards, individual must be aware of his or her own physical activity experience during exercise and they noted that the concept of mindfulness can provide insight into the individual's intrinsic motivational experience. Interest in mindfulness-based interventions to encourage positive health outcomes is growing (Brown, Ryan, \& Creswell, 2007; Gardner \& Moore, 2017), and one powerful outcome of mindfulness might be in fostering individual intrinsic motivation (Ullrich-French et al., 2017). According to Cox et al. (2018), negative affective responses, such as displeasure during exercise, are potentially limiting factors for engaging in regular APA, and these responses may be caused by uncomfortable physical sensations during exercise. Welch, Hulley, Ferguson, and Beauchamp (2007) added that this is particularly true for those who engage in lower physical activity. Recently, Brand and Ekkekakis (2018) introduced an innovative approach to behavior change called the Affective Reflective Theory (ART) of physical inactivity and exercise. The ART is a dual-process theory aimed at explaining why individual, in a state of physical inactivity, does or does not engage in an action. The ART focuses on the psychological processes that govern momentary behavior (e.g., affects) and specifically addresses feelings connected to what individual know about the unpleasant and 
1 pleasant experience they had during exercise. According to Birrer, Rothlin, and Morgan

2 (2012), a mindfulness-based intervention could change behaviour by helping individuals to

3 mindfully experience emotional, affective and cognitive processes. Indeed, as mindfulness

4 includes an indulgent attitude towards negative thoughts, sensations, affects and experiences,

5 it may provide an opening for negative elements to consciously arise. This in turn might then

6 prompt the development of positive coping strategies in such negative circumstances as sports

7 performance, physical activity, and even everyday life (Goodman, Kashdan, Mallard, \&

8 Schumann, 2014). For example, Cox et al. (2018) recently tested the effects of mindfulness

9 during a treadmill-walking task. The authors observed that affective valence was more

10 positive, enjoyment was higher, and perceived exertion was lower in the mindfulness

11 condition than in the control condition. These results suggest that mindfulness is associated with more positive affective responses. Finding effective strategies to enhance affective responses during physical activity is necessary to supporting long-term engagement in APA,

14 which would likely be beneficial to the exerciser's overall health profile (Cox et al., 2018),

15 particularly that of older adults. According to Foutain-Zaragoza and Prakash (2017), older

16 populations are of particular interest given the age-related declines in social support,

17 limitations to physical independence, and decrements in several domains of cognitive function. Based on the assumption that mindfulness is associated with positive affective responses and supports adherence to physical activity, we hypothesized that promoting a mindfulness-based intervention via cell phone would increase APA duration by strengthening 21 intrinsic motivation in adults aged 50 years and older. To our knowledge, this hypothesis has never been investigated and should permit to propose to middle class older adults an innovative and easy-to-implement strategy, based on personal audio guided cognitive activity that would have a positive influence on intrinsic motivation to increase the duration of their 
The aim of this original study was to evaluate whether text messages prompting 10

2 minutes of mindfulness training would increase the weekly minutes of APA in French middle

3 class older adults who were not currently meeting the WHO recommendations. We assumed

4 that the effectiveness of mindfulness, which is a means of modifying cognitions related to

5 intrinsic motivation and creating more pleasant experience, would increase the minutes of

6 APA in the Mindfulness groups. By contrast, in the Control group, the duration of APA

7 would remain stable due to a lack of self-management of negative thoughts related to the

8 exercise that may limit the desire to start or continue a physical activity.

\section{Methods}

\section{Trial design}

As illustrated in Figure 1, the study was a randomized controlled trial with a parallel design of three arms.

\section{Participants}

Eighty-seven older adults gave their informed consent to participate in the study (56 females, 31 males; $M_{\text {age }}=64.35$ years, age range: $50-75$ years). All the eligible participants were volunteers and were recruited from a certified fitness centre for older adults in La Rochelle, France. They all met the following inclusion criteria: (1) minimum 50 years old, (2) member of the fitness centre for at least 6 consecutive months and currently participating in group strength training with a professional fitness instructor at least twice a week, (3) not meeting the WHO recommendation of 150 minutes of weekly APA, and (4) able to receive, read and send e-mail and/or text messages from a cell phone over a 4-week period (see Table

221 for demographic and clinical characteristics for each group). The participant inclusion procedure was similar to that used by Robin et al. (2017). Two participants were excluded because they did not respect the procedure (absence of text message response and no explanation). The experiment was approved by the local ethics committee of the University 
1 (ACTES-3596-0618) and was performed in accordance with the ethical standards laid down

2 in the 1964 Declaration of Helsinki.

3

Table 1 near here

\section{Procedure and Intervention}

At the beginning of the study, the principal investigator collectively addressed to the older adults at the end of strength-training lessons. He asked who would be interested in a non-invasive and easy-to-perform experiment, and presented the inclusion criteria. Then, all the participants attended a meeting where the experimenter presented the procedure, explained how to practice mindfulness based on Kabat-Zinn program (2003), and answered questions. The participants then signed an informed consent form and responded to a personal information questionnaire and a scale of motivation for physical activity in a health context. As illustrated on Figure 1, they were then randomly assigned by lottery to the Mindfulness 1, Mindfulness 2 (with a similar but counterbalanced condition to control for the order effect of the mindfulness practice: Session 1 vs. Session 2) or Control group. The function of the latter group was only to control that the placebo morning text had no influence on weekly physical activity duration, and thus there was no need for counterbalancing (see Robin et al., 2017, for similar procedure). All participants were then randomly and successively exposed to two 2week sessions (session 1: weeks 1-2; session 2: weeks 3-4). A 10-minute audio file containing the mindfulness script was added to the playlist in the cell phones of the Mindfulness group participants. 
The study lasted 4 weeks from $15^{\text {th }}$ September to $13^{\text {th }}$ October 2018 . During session 1

2 (first 2 weeks), the Mindfulness 1 and Control groups received a morning text message (at

3 7:00 am) 3 days a week. In session 2 (second 2 weeks), they did not receive morning

4 messages. The participants of the Mindfulness 2 group received no morning text messages

5 during session 1 (weeks 1-2) and they then received morning text messages during session 2

6 (weeks 3-4). Mindfulness 1 and 2 groups achieved similar but counterbalanced condition (see

7 Figure 1).

The morning text for the Mindfulness groups instructed them to "Listen to the audio

9 file and practise the mindfulness training". The message for the Control group was the exchange rate for the euro from the day before: for example, "1 euro $=1.15$ dollars." After receiving the morning text message, participants of the Control group simply had to send the message "received" to the principal investigator, while the participants of the Mindfulness groups had to send "I did it" after listening to the audio file and practising 10 minutes of 14 mindfulness. The participants of all the groups also received evening text messages, 3 days a week for 4 weeks at 7:30 pm, asking “Did you do your cardio today?” Morning and evening texts were given the same days (i.e., during weeks 1-2 for the Mindfulness 1 and control groups, and during weeks 3-4 for the Mindfulness 2 group). Once the evening text messages were received, all the participants had to complete the APA participation form by cell phone and send it to the principal investigator by respecting a specified answer format. When the response was "yes", the participants were expected to report the type of physical activity (e.g., bike, walk, swim), intensity (moderate or vigorous), and duration (see Robin et al., 2017 for similar procedure).

After the morning text condition, the participants of all the groups completed the motivation for physical activity in a health context scale. Finally, at the end of the experiment 
1 all the participants self-declared that they had respected the protocol and followed the

2 instructions to listen to the audio file when they received the morning text message inviting

3 them (i.e., Mindfulness 1 and 2 groups) to do the mindfulness training. In addition,

4 participants of the Control group received mindfulness audio at the end of the experiment.

\section{Material and Measures}

Development of Mindfulness Manipulation. A 10-minute audio track on mindfulness was created for the participants of the Mindfulness groups. The participants of Mindfulness groups 1 and 2 had to listen this track and practise mindfulness after receiving the morning text message. The track was based on mindfulness scripts that focus on breathing and body sensations. The script brought attention to breathing movements and the air slowly coming in and out of the lungs. Moreover, participants were asked to become aware of their thoughts, without judging them but merely accepting them, and to refocus on their breathing and body sensations. The track contained vocals only and no music or background sounds.

Electronic Aerobic Physical Activity Participation Form. As in the study of Antoine Parker and Ellis (2016), the electronic APA participation form asked two questions: "Did you do your cardio today?" and "If yes, what did you do? If no, why not?" When the participants reported APA, they had to specify the type of activity (e.g., walk, bike, swim, etc.), intensity (moderate or vigorous) and duration (in minutes).

Motivation for Physical Activity in a Health Context Scale. The "Echelle de Motivation envers l'Activité Physique en contexte de Santé” (EMAPS, Boiché et al., 2016) is a French validated scale. Six types of motivation defined by self-determination theory were evaluated: Intrinsic motivation, extrinsic motivation (i.e., integrated regulation, identified regulation, introjected regulation, external regulation), and amotivation. The EMAPS is composed of 18 items ( 3 question per motivation type), and each item is rated on a 7-point Likert-type scale (from $1=$ does not fit at all to $7=$ correspond strongly). 
Data Analysis

To determine whether the two Mindfulness groups could be combined into one group,

morning message condition vs. Mindfulness 2: No morning message condition followed by

mindfulness morning message condition) was explored by a two-way ANOVA on APA

duration with a group factor and a session factor. We then performed a two-way ANOVA on

APA duration to explore the effect of condition and session. Other two-way ANOVAs

explored the effects of condition and session on the EMAPS scores for the six types of

motivation for the whole sample. Data analyst was kept blinded to the allocation group. For all analyses, the significant interactions were broken down using the Newman-Keuls test.

Normality was checked (Kolmogorov-Smirnov test), effect sizes $\left(\eta_{\mathrm{p}}{ }^{2}\right)$ were indicated, and $\alpha$ was set at .05 for all the analyses.

\section{Results}

\section{Mindfulness Training and Aerobic Physical Activity}

The weekly minutes of APA according to the experimental groups are presented as means and standard deviations (see Table 2). The first two-way ANOVA revealed no order effect on minutes of APA in either of the two Mindfulness groups, $F(1,54)=0.05, p=.82$, $\eta_{\mathrm{p}}{ }^{2}=0.00$. The two groups were therefore combined into one of 56 participants.

An ANOVA was then performed to explore the effect of group (Mindfulness vs.

Control) on minutes of APA with the type of morning message (mindfulness vs. placebo) as a between-subject factor and repetition (morning message vs. no morning message) as a withinsubject factor.

The ANOVA revealed no significant main effect of group, $F(1,83)=2.83, p=.09, \eta_{\mathrm{p}}{ }^{2}$

$24=0.03$, but yielded a significant main effect of type of morning message, $F(1,83)=24.31, p=$ 
1 between group and type of morning message, $F(1,83)=28.90, p=.000, \eta_{\mathrm{p}}{ }^{2}=0.26$. As

2 illustrated on Figure 2, the post-hoc Newman-Keuls test revealed that the participants of the

3 Mindfulness group reported significantly more average weekly minutes of APA $(M=114.48)$

4 in the morning message condition compared with the no morning message condition $(M=$

5 90.50). Moreover, the participants of the Control group showed no significant difference

6 between the morning message condition $(M=90.69)$ with a placebo text and the no morning

7 message condition $(M=91.72)$. Finally, in the morning message condition, participants of the

8 Mindfulness group reported significantly more average weekly minutes of APA than the

9 participants of the Control group.

None of the participants reported vigorous APA in their electronic responses.

11

Table 2 and Figure 2 near here

\section{Mindfulness Training and Motivation}

As illustrated on table 3, the ANOVAs performed on EMAPS scores revealed no significant difference between the Mindfulness 1 and Mindfulness 2 groups at the preexperimental session on intrinsic motivation $\left[F(1,54)=0.55, p=.81, \eta_{\mathrm{p}}{ }^{2}=0.00\right]$, the extrinsic motivation types (all $p \mathrm{~s}>.05$ and all $\eta_{\mathrm{p}}{ }^{2}=0.00$ ), or amotivation $\left[F(1,54)=0.01 p=.92, \eta_{\mathrm{p}}{ }^{2}=\right.$ 0.00]. Moreover, there was no significant difference between the Mindfulness 1 and Mindfulness 2 groups after the mindfulness morning message session on intrinsic motivation $\left[F(1,54)=0.03, p=.85, \eta_{\mathrm{p}}{ }^{2}=0.00\right]$, the extrinsic motivation types (all $p s>.05$ and all $\eta_{\mathrm{p}}{ }^{2}=$ $0.00)$, or amotivation $\left[F(1,54)=0.01, p=.94, \eta_{\mathrm{p}}{ }^{2}=0.00\right]$. The EMAPS scores (i.e., for intrinsic, extrinsic and amotivation) of Mindfulness groups 1 and 2 were therefore combined. 
We then performed ANOVAs on the EMAPS scores with group (Mindfulness vs.

2 Control) as a between-subject factor and moment (before vs. after the morning message

3 session) as a within-subject factor.

4

5

6

7

The ANOVA on the EMAPS intrinsic motivation score revealed no significant main effect of group, $F(1,83)=1.79, p=.18, \eta_{\mathrm{p}}{ }^{2}=0.02$, but did reveal a significant main effect of moment, $F(1,83)=7.65, p=.007, \eta_{\mathrm{p}}{ }^{2}=0.08$. Moreover, the ANOVA showed a significant interaction between group and moment, $F(1,83)=13.33, p=.000, \eta_{\mathrm{p}}{ }^{2}=0.14$. The post-hoc Newman-Keuls test revealed that the participants of the Mindfulness group had higher intrinsic motivation scores after the morning message session than at the pre-experimental session.

Table 3 and Figure 3 near here

The ANOVAs on the EMAPS scores for extrinsic motivation types revealed no significant main effect of group, moment, or interaction between group and moment (all $p \mathbf{s}>$ $.05)$.

The ANOVA on the EMAPS amotivation score revealed no significant main effect of group, $F(1,83)=1.01, p=.32, \eta_{\mathrm{p}}{ }^{2}=0.01$, or moment, $F(1,83)=3.64, p=.06, \eta_{\mathrm{p}}{ }^{2}=0.04$.

Moreover, the ANOVA revealed a significant interaction between group and moment, $F(1,83)$ $=11.47, p=.001, \eta_{\mathrm{p}}{ }^{2}=0.12$. The post-hoc Newman-Keuls test showed that the participants of the Mindfulness group had lower amotivation scores after the morning message session than during the pre-experimental session. 


\section{Discussion}

\section{Generalizability}

The aim of the current study was to determine whether text messages prompting participants to perform 10 minutes of mindfulness training would be a successful strategy for increasing weekly minutes of APA among French middle class older adults. The results of this original study extend the literature by providing evidence that text messages promoting mindfulness via cell phones can increase APA duration in adults 50 years and older. In addition, the current study has offered the older adults an innovative and easy-to-implement strategy to increase the duration of APA. Indeed, the participants of the Mindfulness groups increased their APA by $26.5 \%$ (with a sample size $\eta_{\mathrm{p}}{ }^{2}=0.26$ ) under the mindfulness morning text message condition, whereas there was no evolution for the Control group throughout the entire experiment. It is important to note that the increase in APA after the mindfulness prompts was slightly lower than that observed in the studies of Antoine Parker and Ellis (2016), which used prompts like “Don't forget to do cardio today", and Robin et al. (2017), which used imagery (35.2 \% and $36.8 \%$, respectively). As noted, it is possible that the participants might have needed more mindfulness training sessions to optimally benefit from the positive effects of this strategy. Indeed, for athletes, Pineau, Glass, and Kaufman (2014) recommended intervention periods of mindfulness practice longer than 4 weeks to ensure beneficial effects. However, it is also important to note that six participants of Mindfulness 1 and five participants of Mindfulness 2, making up 19.6\% of the participants using the mindfulness strategy, met the WHO recommendation of 150 minutes of APA a week after a few mindfulness training sessions. This result, albeit limited, is encouraging given that none of the participants reached this recommendation before the experiment or during the no morning message condition. Mindfulness-based interventions seem to be useful to improve 
1 as this strategy had positive effects for younger participants (Ullrich-French et al., 2017),

2 pregnant women (Martinez-Paredes \& Jacome-Perez, 2019), or cancer survivors (for a

3 review, see Mehta, Sharma, Potters, Wernicke, \& Parashar, 2019) in different domains. This

4 strategy could be used to complete or replace other techniques that suggest or requires one to

5 imagine engaging in APA (Antoine Parker \& Ellis, 2016; Robin et al., 2017), which could be

6 beneficial for poor imagers, or other peoples who prefer the use of mindfulness or for whom

7 other strategies would not be appropriate. According to Gardner and Moore (2017), there is

8 growing interest in mindfulness-based interventions to encourage positive health outcomes,

9 and one powerful outcome of this strategy might be in fostering intrinsic motivation (Ullrich-

10 French et al., 2017).

11 Interpretation

12 The results of this study provide evidence that text messages promoting mindfulness

13 training increase weekly minutes of APA among older adults. These findings are in line with

14 those of Foutain-Zaragoza and Prakash (2017), who noted that mindfulness-based strategies

15 are particularly useful for older adults because they provide physiological, cognitive and

16 emotional benefits. Mindfulness is known to facilitate natural emotion regulation strategies

17 (Geiger et al., 2016), promote psychological well-being (Fiocco \& Mallya, 2015), reduce

18 perceived stress (Prakash et al., 2015) or pain (Morone, Lynch, Greco, Tindle, \& Weiner,

19 2008). Mindfulness is also known to enhance attentional control, preserved neural functioning

20 (Prakash et al., 2012), reduce systemic inflammation in older adults (Creswell et al., 2012),

21 and have a beneficial influence on physical activity (Kennedy \& Resnick, 2015). The results

22 obtained in the present study show that mindfulness, known to facilitate physical activity in

23 athletes (Bernier, Thienot, Pelosse, \& Fournier, 2009), is also beneficial to older adults during

24 leisure physical activities. The potential beneficial effects of this strategy on APA duration in

25 older adults have been little studied. It thus seems important to open this line of research in

26 order to propose other effective, simple and easy-to-implement strategies to encourage older 
1 adults to be more active.

As noted, recent studies have reviewed the beneficial effects of mindfulness on

3 healthy ageing, particularly with regard to attention, inflammation, and physical and

4 emotional well-being (Foutain-Zaragoza \& Prakash, 2017; Geiger et al., 2016). In addition to

5 the beneficial effects noted in earlier studies, the results of the current study showed that

6 mindfulness training is an effective intervention for increasing APA in older adults who

7 regularly engage in physical activities by strengthening intrinsic motivation. Indeed, the participants of the Mindfulness groups had significantly higher EMAPS intrinsic motivation scores after the morning text message sessions than during the pre-experimental session, whereas the scores of the Control group participants remained stable across the experimental sessions and extrinsic motivation remained unchanged whatever the group and experimental condition. These results are consistent with the findings of Ullrich-French and collaborators (2017), who suggested an increased likelihood of engaging in physical activity when people choose to be active of their own volition or have autonomous reasons (Wilson, Rodgers, Fraser, \& Murray, 2004). According to self-determination theory (Ryan \& Deci, 2007), intrinsic motivation is the most autonomous type of motivation and it is believed to be the best predictor of adherence to physical activity. Regular physical activity seems to be facilitated when participants are motivated by the inherent benefits of the activity itself rather than by external contingencies. According to Ullrich-French et al. (2017), the construct of mindfulness offers insight into intrinsic motivational experience, and changes behaviour by helping participants to mindfully experience emotional, affective and cognitive processes

22 (Birrer et al., 2012). Being indulgent towards negative thoughts, affects and experiences, mindfulness-based interventions facilitate positive coping with negative circumstances in sports situations and daily life (Goodman et al., 2014). In addition, the latter interpretation 
1 exercise (Brand \& Ekkekakis, 2018) that proposes that individual activity be more likely to

2 reflect their affect-driven urges rather than their deliberative decisions. Finally, the results of

3 this study revealed that the participants of the Mindfulness groups had lower amotivation (i.e.,

4 absence of intentionality) scores after the morning message session than during the pre-

5 experimental session. This result, suggesting that mindfulness could increase the

6 intentionality to engage in APA, needs to be confirmed in future research.

\section{$7 \quad$ Limitations}

For a mindfulness-based intervention, the duration of the morning text message condition ( 2 weeks) might be considered short, despite its positive effects on APA. However, it is important to note that the objective of this study was to evaluate whether text messages to prompt mindfulness training would increase minutes of APA in older adults and to compare our results with those obtained in previous studies using similar protocols (e.g., Antoine Parker \& Ellis, 2016; Prestwich, Perugini, \& Hurling, 2010; Robin et al., 2017). The current study should thus be viewed as a short-duration intervention that demonstrates the effectiveness of prompts for changing behaviour (Fry \& Neff, 2009; Kim \& Glanz, 2013; Robin et al., 2017). Although the results of this study are promising, suggesting the positive effects of mindfulness to promote short-term APA in French middle class older adults, further research is needed to evaluate whether this strategy is effective for long-term adherence to APA (i.e., 6 months and more) and whether it would be beneficial to the exerciser's overall health profile (Cox et al., 2018) and to older adults from other class, culture, educational

21 levels. The self-reporting of APA minutes might be another limitation, although its use has 22 been reported in many studies (e.g., Antoine Parker \& Ellis, 2016; Prestwich et al., 2010; Robin et al., 2017), and it is possible that a few participants under- or overestimated their minutes of APA. Further studies using heart rate monitoring and pedometers (e.g., fitness tracker watch) will be done in our laboratory to have objective measurements of APA. 
1 Finally, future studies, questioning the correlations between each dimension of the EMAPS

2 could adopt a MANOVA approach rather than a series of ANOVAs.

3

4

\section{Conclusion}

The present study confirmed that text messages prompting 10 minutes of mindfulness training increase the weekly minutes of APA in French middle class older adults who have the means and ability to access a mobile phone, to exercise regularly but did not currently meet the WHO recommendations. As suggested by Kennedy and Resnick (2015), prescribing mindfulness-training interventions may be another resource to help motivate individuals to exercise and become more physically active, and this intervention strategy is one way to initiate aerobic physical activity as well as improve intrinsic motivation and decrease amotivation.

This research received no specific grant from any funding agency in the public, commercial, or not-for-profit sectors.

\section{References}

Albinet, C., Boucard, G., Bouquet, C., \& Audiffren, M. (2010). Increased heart rate variability and executive performance after aerobic training in the elderly. European Journal of Applied Physiology, 109, 617-624. doi:10.1007/s00421-010-1393-y

Alexander, C. N., Langer, E. J., Newman, R. I., Chandler, H. M., \& Davies, J. L. (1989). Transcendental meditation, mindfulness, and longevity: An experimental study with the elderly. Journal of Personnality and Social Psychology, 57, 950-964. doi:10.1037/0022-3514.57.6.950 
1 Anderson, M., \& Perrin, A. (2017). Tech adoption climb among older adults. Pew research center, may 2017. http://assets.pewresearch.org/wpcontent/uploads/sites/14/2017/05/16170850/PI_2017.05.17_Older-AmericansTech_FINAL.pdf

Antoine Parker, C., \& Ellis, R. (2016). Effect of electronic messaging on physical activity participation among older adults. Journal of Aging Research, 1-6. doi:10.1155/2016/6171028

Bernier, M., Thienot, E., Pelosse, E., \& Fournier, J. F. (2014). Effects and underlying processes of a mindfulness-based intervention with young elite figure skaters: Two case studies. Sport Psychologist, 28(3), 302-315. doi:10.1123/tsp.2013-0006.

Birrer, D., Rothlin, P., \& Morgan, G. (2012). Mindfulness to enhance athletic performance: theoretical considerations and possible impact mechanisms. Mindfulness, 3(3), 23546.

Bishop, S. R., Lau, M., Shapiro, S., Carlson, L., Anderson, N. D., Carmody, J., ... Devins, G. (2004). Mindfulness: A proposed operational definition. Clinical Psychology Science and Practice, 11, 230-241. doi:10.1093/clipsy.bph077

Boiché, J., Gourlan, M., Trouilloud, D., \& Sarrazin, P. (2016). Development and validation of the 'Echelle de Motivation envers l'Activité Physique en contexte de Santé': A motivation scale towards health-oriented physical activity in French. Journal of Health Psychology.

Brand, R., \& Ekkekakis, P. (2018). Affective-reflective theory of physical inactivity and exercise. German Journal of Exercise and Sport Research, 48(1), 48-58.

Brown, K. W., \& Ryan, R. M. (2003). The benefits of being present: Mindfulness and its role in psychological well-being. Journal of Personality and Social Psychology, 84, 822848. doi:10.1037/0022-3514.84.4.822 
1 Brown, K. W., Ryan, R. M., \& Creswell, J. D. (2007). Mindfulness: Theoretical foundations and evidence for its salutary effects. Psychological Inquiry, 18, 211-237.

3 Charansonney, O. L. (2011). Physical activity and aging: A life-long story. Discovery Medicine, 12(64), 177-185.

Cole-Lewis, H., \& Kershaw, T. (2010). Text messaging as a tool for behavior change in disease prevention and management. Epidemiologic Reviews, 32, 56-69. doi:10.1093/epirev/mxq004

Cox, A. E., Roberts, M. A., Cates, H. L., \& McMahon, A. K. (2018). Mindfulness and affective responses to treadmill walking in individuals with low intrinsic motivation to exercise. International Journal of Exercise Science, 11(5), 609-624.

Creswell, J. D., Irwin, M. R., Burklund, L. J., Lieberman, M. D., Arevalo, J. M., Ma, J., et al. (2012). Mindfulness-based stress reduction training reduces loneliness and proinflammatory gene expression in older adults: A small randomized controlled trial. Brain Behavior and Immunity, 26, 1095-1101. doi: 10.1016/j.bbi.2012.07.006

Deci, E. L., \& Ryan, R. M. (1985). Intrinsic Motivation and Self-regulation in Human Behavior. New York: Plenum.

Deci, E. L., \& Ryan, R. M. (2008). Facilitating optimal motivation and psychological wellbeing across life's domains. Canadian Psychology, 49, 14-23.

Denison, E., Vist, G. E., Underland, V., \& Berg, R. C. (2014). Interventions aimed at increasing the level of physical activity by including organised follow-up: A systematic review of effect. BMC Family Practice, 15, 120. doi:10.1186/1471-2296$15-120$

Dionigi, R., \& Gard, M. (2018). Sport and physical activity across lifespan: Critical perspectives. Basingstoke, United Kingdown: Palgrave Macmillan. doi:10.1057/978$1-137-48562 \_1$ 
1 Duncan, M., Vandelanotte, C., Kolt, G. S., Rosenkranz, R. R., Caperchione, C. M., George, E. S., . . Mummery, W. K. (2014). Effectiveness of a web- and mobile phone-based intervention to promote physical activity and healthy eating in middle-aged males: Randomized controlled trial of the ManUp study. Journal of Medical Internet Research, 16(6), e136. doi:10.2196/jmir.3107

Elsawy, B., \& Higgins, K. E. (2010). Physical activity guidelines for older adults. American Family Physician, 81(1), 55-59.

Fanning, J., Mullen, S. P., \& McAuley, E. (2012). Increasing physical activity with mobile devices: A meta-analysis. Journal of Medical Internet Research, 14, 161-177. doi:10.2196/jmir.2171

Fiocco, A. J., \& Mallya, S. (2015). The importance of cultivating mindfulness for cognitive and emotional well- being in late life. Journal of Evidence-Based Complementary \& Alternative Medicine, 20, 35-40.

Fjeldsoe, B. S., Marshall, A. L, \& Miller, Y. D. (2009). Behavior change interventions delivered by mobile telephone short-message service. American Journal of Preventive Medicine, 36(2), 165-73.

Fong, S. S., Ng, S. S., Cheng, Y. T., Zhang, J., Chung, L. M., Chow, G. C., . . . Macfarlane, D. J. (2016). Comparison between smartphone pedometer applications and traditional pedometers for improving physical activity and body mass index in communitydwelling older adults. Journal of Physical Therapy Science, 28(5), 1651-1656. doi:10.1589/jpts.28.1651

Foutain-Zaragoza, S., \& Prakash, R. S. (2017). Mindfulness training for healthy aging: Impact on attention, well-being, and inflammation. Frontiers in Aging Neuroscience, 9, 11. doi:10.3389/fnagi.2017.00011 
1 Fry, J. P., \& Neff, R. A. (2009). Periodic prompts and reminders in health promotion and health behavior interventions: Systematic review. Journal of Medical Internet Research, 11, e16.

Gardner, F. L., \& Moore, Z. E. (2017). Mindfulness-based and acceptance-based interventions in sport and performance contexts. Current Opinion in Psychology, 16, 180-184. http://dx.doi.org/10.11016/j.copsyc.2017.06.001

Gell, N. M., Rosenberg, D. E., Demiris, G., LaCroix, A. Z., \& Patel, K. V. (2015). Patterns of technology use among older adults with and without disabilities. Gerontologist, 55(3), 412-421. doi:10.1093/geront/gnt166

Geiger, P. J., Boggero, I. A., Brake, C. A., Caldera, C. A., Combs, H. L., Peters, J. R., ... \& Baer, R. (2016). Mindfulness-based interventions for older adults: A review of the effects on physical and emotional well-being. Mindfulness, 7, 296-307. doi:10.1007/s12671-015-0444-1

Goodman, F. R., Kashdan, T. B., Mallard, T. T., \& Schumann, M. (2014). A brief mindfulness and yoga intervention with an entire NCAA division I athletic team: An initial investigation. Psychology of Consciousness: Theory Research and Practice, 1, 339-56. http://dx.doi.org/10.1037/cns0000022

Hughes, S. L, Leith, K. H., Marquez, D. X., Ba, G. M., Nguyen, H. Q., Pankaja Desai, R., ... Jones, D. L. (2011). Physical activity and older adults: Expert consensus for a new research agenda. Gerontologist, 51(6), 822-32.

Joe, J., \& Demeris, G. (2013). Older adults and mobile phones for health: A review. Journal of Biomedical Informatics, 46(5), 947-954.

Johnston, W., Hoffman, S., \& Thornton, L. (2014). Mobile health: A synopsis and comment on "Increasing physical activity with mobile devices: A meta-analysis". Translational Behavioral Medicine, 4(1), 4-6. doi:10.1007/s13142-014-0254-3 
1 Kabat-Zinn, J. (2003). Mindfulness-based interventions in context: Past, present, and future. Clinical Psychology: Science and Practice, 10(2), 144-156. http://dx.doi.org/10.1093/clipsy/bpg016

Kennedy, A. B., \& Resnick, P. B. (2015). Mindfulness and Physical Activity. American Journal of Lifestyle Medicine, 9(3), 221-223.

Kim, B. H., \& Glanz, K. (2013). Text messaging to motivate walking in older African Americans: A randomized controlled trial. American Journal of Preventive Medicine, 44, 71-75.

Leavy, J. E., Bull, F., Rosenberg, M., \& Bauman, A. (2011). Physical activity mass media campaigns and their evaluation: A systematic review of the literature 2003-2010. Health Education Research, 26, 1060-1085.

Martinez-Paredes, J., \& Jacome-Perez, N. (2019). Depression in pregnancy. Revista Colombiana de Psiquiatría, 48(1), 58-65.

McPhee, J. S., French, D. P., Jackson, D., Nazroo, J., Pendleton, N., \& Degens, H. (2016). Physical activity in older age: Perspectives for healthy ageing and frailty. Biogerontology, 17(3), 567-580. doi:10.1007/s10522-016-9641-0

Mehta, R., Sharma, K., Potters, L., Wernicke, A. G., \& Parashar, B. (2019). Evidence for the role of mindfulness in cancer: Benefits and techniques. Cureus, 11(5), e4629. doi: $10.7759 /$ cureus.4629

Morone, N. E., Lynch, C. S., Greco, C. M., Tindle, H. A., \& Weiner, D. K. (2008). I felt like a new person. The effects of mindfulness meditation on older adults with chronic pain: qualitative narrative analysis of diary entries. The Journal of Pain, 9, 841-848. doi: 10.1016/j.jpain.2008.04.003

Morton, K., Sutton, S., Hardeman, W., Troughton, J., Yates, T., Griffin, S., . . Eborall, H. (2015). A Text-Messaging and Pedometer Program to Promote Physical Activity in 
People at High Risk of Type 2 Diabetes: The development of the PROPELS follow-on support program. JMIR Mhealth and Uhealth, 3(4), e105. doi:10.2196/mhealth.5026

Muller, A. M., Khoo, S., \& Morris, T. (2016). Text messaging for exercise promotion in older adults from an upper-middle-income country: Randomized controlled trial. Journal of Medical Internet Research, 18(1), e5. doi:10.2196/jmir.5235

Norris, C. J., Creem, D., Hendler, R., \& Kober, H. (2018). Brief mindfulness meditation improves attention in novices: Evidence from ERPs and moderation by neuroticism. Frontiers in Human Neuroscience, 12, 315. doi:10.3389/fnhum.2018.00315

O'Reilly, G. A., \& Spruijt-Metz, D. (2013). Current mHealth technologies for physical activity assessment and promotion. American Journal of Preventive Medicine, 45(4), 501-507. doi:10.1016/j.amepre.2013.05.012

Pineau, T. R., Glass, C. R., \& Kaufman, K. A. (2014). Mindfulness in sport performance. In: Ie A, Ngnoumen CT, Langer EJ, editors. Handbook of mindfulness. (pp. 1004-34). Oxford: Wiley-Blackwell.

Prakash, R. S., Hussain, M. A., \& Schirda, B. (2015). The role of emotion regulation and cognitive control in the association between mindfulness disposition and stress. Psychology and Aging, 30(1), 160-171. doi:10.1037/a0038544

Prakash, R., Rastogi, P., Dubey, I., Abhishek, P., Chaudhury, S., \& Small, B. J. (2012). Longterm concentrative meditation and cognitive performance among older adults. Aging Neuropsychology Cogition, 19, 479-494. doi: 10.1080/13825585.2011.630932

Prestwich, A. Perugini, M., \& Hurling, R. (2010). Can implementation intentions and text messages promote brisk walking? A randomized trial. Health Psychology, 29, 40-49.

Robin, N., Toussaint, L., Coudevylle, G. R., Stuart, S., Hue, O., \& Sinnapah, S. (2017). Mental imagery promoted by text messaging can increase self-reported physical 
exercise in elderly. Journal of Aging and Physical Activity, 26(3), 462-470. Retrieved from: https://doi.org/10.1123/japa.2017-0069

Ryan, R. M., \& Deci, E. L. (2007). Active human nature: Self-determination theory and the promotion and maintenance of sport, exercise, and health. In M. S. Hagger \& N. Chatzisarantis (Eds.), Intrinsic motivation and self-determination in exercise and sport (pp. 1-19). Champaign, IL: Human Kinetics.

Studenski, S., Perera, S., Hile, E., Keller, V., Spadola-Bogard, J., \& Garcia, J. (2010). Interactive video dance games for healthy older adults. Journal of Nutrition Health and Aging, 14(10), 850-852.

Sun, F., Norman, I. J., \& While, A. E. (2013). Physical activity in older people: A systematic review. BMC Public Health, 13, 449. doi:10.1186/1471-2458-13-449

Taylor, D. (2014). Physical activity is medicine for older adults. Postgraduate Medical Journal, 90(1059), 26-32. doi:10.1136/postgradmedj-2012-131366

Teixeira, P. J., Carraça, E. V., Markland, D., Silva, M. N., \& Ryan, R. M. (2012). Exercise, physical activity, and self-determination theory: A systematic review. International Journal of Behaviorla Nutrition and Physical Activity, 9(1), 1-30.

Ullrich-French, S., Gonzales Hernandez, J. G., \& Hidalgo Montesinos, M. D. (2017). Validity evidence for the adaptation of the State Mindfulness Scale for Physical Activity (SMSPA) in spanish youth. Psicothema, 29(1), 119-125.

Vandelanotte, C., Short, C., Plotnikoff, R. C., Hooker, C., Canoy, D., Rebar, A., . . Duncan, M. J. (2015). TaylorActive-Examining the effectiveness of web-based personallytailored videos to increase physical activity: A randomised controlled trial protocol. BMC Public Health, 15, 1020. doi:10.1186/s12889-015-2363-4 
1 Warburton, D. (2009). The physical activity and exercise continuum. In C. Bouchard \& P. T. Katzmarzyk (Eds.), Advances in physical activity and obesity (pp. 21-30). Champaign IL: Human Kinetics Publishing.

Welch, A. S., Hulley, A., Ferguson, C., \& Beauchamp, M. R. (2007). Affective responses of inactive women to a maximal incremental exercise test: A test of the dual-mode model. Psychology of Sport and Exercise, 8(4), 401-423.

Wilson, P. M., Rodgers, W. M., Fraser, S. N., \& Murray, T. C. (2004). Relationships between exercise regulations and motivational consequences in university students. Research Quarterly for Exercise and Sport, 75, 81-91.

World Health Organization. Global status report on noncommunicable diseases 2010. Geneva: WHO Press; 2011.

12 World Health Organization Diet and Physical Activity Factsheet. Secondary Diet and Physical Activity Factsheet 2013. 